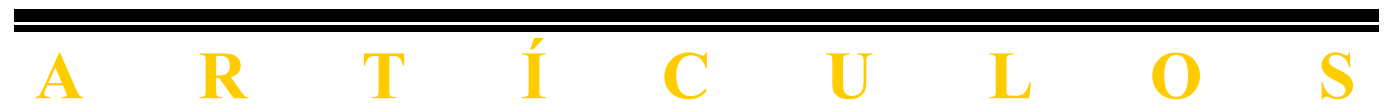




\section{EL CONCEPTO SOCIOLÓGICO DEL DERECHO}

\section{Enfoques teórico-normativos y sociológicos del Derecho}

1 problema que me interesa analizar en lo que sigue fue ya claramente descrito por Immanuel Kant en su Metafísica de las costumbres de $1797^{1}$. En su «Introducción a la teoría del Derecho» -que fuera concebida por él como una parte de la teoría de la moralidad- dice $\mathrm{Kant}^{2}$ con respecto a la pregunta "¿Qué es el Derecho?» que ella provoca entre los juristas la misma perplejidad que entre los lógicos la pregunta «¿Qué es la verdad?». Kant procura hacer frente a las dificultades gnoseológicas y epistemológicas que plantea esta pregunta dividiéndola en otras dos, es decir, 1) la pregunta acerca de que «¿Qué es Derecho? (quid sit iuris)» y 2) la pregunta acerca de si lo que las leyes quieren «también es conforme a Derecho», es decir, correcto en el sentido de que puede ofrecer un criterio para la distinción entre lo justo y lo injusto (iustum et iniustum). Kant consideraba que podía darse una respuesta a la primera pregunta recurriendo a aquello «que las leyes dicen o han dicho en un cierto lugar y en un cierto tiempo». En cambio, la respuesta a la segunda pregunta sería posible sólo si el jurista estuviera dispuesto a abandonar por lo menos «por un tiempo aquellos principios empíricos» y a buscar «las fuentes de aquellos juicios en la mera razón» a fin de «construir los fundamentos de una posible legislación positiva» ${ }^{3}$.

1. Manifiestamente, Kant sustentaba una posición muy crítica con respecto a la posibilidad de una teoría empírica del Derecho -cuyas fuentes debían ser buscadas no sólo en la razón, sino también en los datos históricos y sociales-, pues observa, algo despectivamente, que: «Una teoría del Derecho meramente empírica es (como la cabeza de madera en la fábula de Fedro)

${ }^{1}$ Immanuel Kant, Metaphysik der Sitten. En lo que sigue citado según la Werkausgabe (WW) en seis tomos editada por Wilhelm Weischedel. Citada según la reimpresión de Darmstadt, 1956 ss. Aquí WW IV, págs. 303 ss., 309 ss.

${ }^{2}$ Ibid., pág. 336.

${ }^{3} \mathrm{Al}$ respecto y para lo que sigue, ibíd., pág. $336 \S \mathrm{B}$. 
una cabeza que puede ser bella pero que, desgraciadamente, no tiene cerebro ${ }^{4} . \gg$ Frente a esta autoapriorización del pensamiento kantiano, uno se siente tentado a reaccionar con una reformulación mucho más escéptica con respecto a las posibilidades del conocimiento jurídico pero orientada empíricamente y que parte de las condiciones histórico-sociales de todo Derecho, que determinan y signan también todo conocimiento del Derecho. Según esta posición, una teoría del Derecho meramente racional es, como la cabeza de madera en la fábula de Fedro, una cabeza que puede ser bella, pero que, desgraciadamente, no puede tener vivencias ni percepciones, no puede observar, describir y explicar. En lo que sigue -a diferencia de Kant y de los neokantianos- me propongo demostrar que la cabeza que desde el comienzo desea diseñar una teoría del Derecho genuinamente empírica no necesita en absoluto ser de madera y descerebrada, es decir, carecer de toda razón, tal como pensaba Kant. Por el contrario, me parece sumamente irracional pretender fundamentar una teoría y una sociología del Derecho de alguna otra manera que no sea empírica, es decir, apoyada en percepciones, en observaciones controladas y en experiencias realizadas.

2. No hay duda que, gracias a la orientación que Kant impusiera al desarrollo de la ciencia del Derecho, desde el siglo XIX (i) pasó a primer plano la praxis humana de la acción y del conocimiento; (ii) se concedió a toda praxis jurídica prioridad frente a la teorización, y (iii) por lo que respecta a la teorización que elabora la praxis jurídica cotidiana, se estimularon decididamente los esfuerzos en aras de una fundamentación gnoseológica y epistemológica ${ }^{5}$. Pero, en virtud de la división del cuestionamiento, señalada más arriba, la definición del concepto de Derecho y la ulterior teorización no fueron conducidas por una vía histórico-social, sino por la vía meramente «racional» de la filosofía del Derecho y de la moral o, dicho modernamente, fueron desplazadas a la teoría de la justicia ${ }^{6}$. También hoy resulta

${ }^{4}$ Ibid., pág. 336.

${ }^{5}$ Para mayores detalles: Werner Krawietz, «Normativismus oder Skeptizismus? Zum Verhältnis von Regelsetzung und Regelbefolgung in der kritischen Rechtstheorie Kants», en la del mismo autor Walter Ott (comps.), Formalismus und Phänomenologie im Rechisdenken der Gegenwart, Berlín, 1987, págs. 321-342, 323 s., 339.

${ }^{6}$ Entendida aquí en el sentido de Rawls, Nozick, Buchanan y Dworkin. Al respecto, cfr. Peter Koller, Neue Theorien des Sozialkontrakts, Berlín, 1987. Cfr. además, Werner Krawietz, «Kontraktualismus oder Konsozialismus?», en K. W. Dahm y otros (comps.), Politische Theorie des Johannes Althusius, Berlín, 1988, págs. 391-423, 402 ss. 
obvio que Kant -no obstante todos los esfuerzos con miras a una fundamentación apriorística de su definición del Derecho- no logró desarrollar una teoría del Derecho satisfactoria, tanto desde el punto de vista práctico como teórico. Sólo en época reciente se ha percibido la peculiaridad y originalidad de su teoría del Derecho y su contribución crítica -también sociológicamente relevante- a la definición del concepto del Derecho, algo que, debido a que su teoría del Derecho estaba incluida en su Metafísica de las costumbres, durante largo tiempo permaneció oculto ${ }^{7}$.

3. En lo que sigue, parto del cambio en el pensamiento jurídico, que en el caso de la ciencia alemana del Derecho se produjo sobre todo a raíz de la decisiva influencia de los críticos de Kant y su teoría del Derecho ${ }^{8}$, que ya a mediados del siglo XIX condujera a un concepto sociológico del Derecho. Se trataba aquí de un tan profundo cambio en el diseño total de la acción y la investigación de la jurisprudencia, de la teoría y la filosofía del Derecho que, sin exageración, puede hablarse de un cambio de paradigma que revolucionó todas las concepciones jurídicas anteriores. Tal como lo he expuesto en otro lugar', este cambio se llevó a cabo en dos fases. En la primera, ya a fines del siglo XVIII, bajo la influencia de las críticas de Kant, tuvo lugar una paulatina disolución y superación del pensamiento tradicional, metafisico-especulativo, del Derecho natural y racional; en la segunda fase, se produjo el vuelco a una jurisprudencia sociológica, vinculado con la obra pionera de Thering y que externamente está claramente marcado por la publicación de los dos tomos de su obra tardía El fin en el Derecho, en los años 1877 y 1883 . Esta obra constituye también el paso a una fundamentación sociológica del Derecho y, con ello, se convierte en un hito esencial del desarrollo del pensamiento jurídico a partir del siglo XIX.

4. Pero antes de entrar a analizar las diferentes posibilidades teóricas de un acceso sociológico al Derecho, parece oportuno introducir una limitación más. Por lo que respecta a las posiciones

${ }^{7}$ Krawietz, «Normativismus...», págs. 338 s., 340.

${ }^{8}$ Kant, Kritik der reinen Vernunft, 1781; del mismo autor, Kritik der praktischen Vernunft, 1788; del mismo autor, Kritik der Urteilskraft, 1790. Cfr. además, del mismo autor, Grundlegung zur Metaphysik der Sitten, 1785; del mismo autor, Metaphysik tler Sitten, 1797. Cfr. al respecto, Jürgen Blühdorn, «'Kantianer' und Kant. Die Wende von Rechtsmetaphysik zur 'Wissenschaft' vom positiven Recht», en Kant-Studien, 64 (1973), págs. 363-394.

${ }^{9}$ Werner Krawietz, «Zum Paradigmenwchsel im Juristischen Methodenstreit», en, del mismo autor, Kazimierz Opalek y otros (comps.), Argumentation und Hermeneutik in der Jurisprudenz, Berlín, 1979, págs. 113-152, 131 ss. 
frente al Derecho y la sociología del Derecho, cabe señalar que -prescindiendo de algunas excepciones a las que habré de referirme de inmediato- la sociología del Derecho germano-occidental se ha limitado en los últimos decenios a una investigación social empírica, más o menos ateórica ${ }^{10}$. También la reciente sociología del Derecho germano-occidental ha insistido en amplios ámbitos y con demasiada diligencia en una investigación empírica de proyectos por encargo ${ }^{11}$, sin prestar la debida atención a la investigación básica teórico-jurídica y jurídico-sociológica. Y, finalmente, hasta el día de hoy falta una recepción y elaboración adecuadas de lo logrado en los últimos decenios en la teoría de las normas, tanto a nivel nacional, como internacional ${ }^{12}$. Sólo en época reciente, en la llamada investigación jurídica empírica ${ }^{13}$, comienza -aunque algo tímidamente- a tomarse conciencia de que con la mera obtención de información a través de la llamada investigación de los hechos jurídicos, no se gana mucho por lo que respecta al conocimiento del Derecho ya que este último depende y seguirá dependiendo en gran medida de la teoría ${ }^{14}$.

5. Actualmente, por lo que respecta a la conceptuación teórico-jurídica y jurídico-sociológica del Derecho, luchan por su reconocimiento numerosos enfoques de explicación teórico-normativos, cada uno de los cuales considera como característicos de la estructura de la norma jurídica o del orden jurídico diferentes elementos del Derecho. En sus recientemente publicados

${ }^{10} \mathrm{Al}$ respecto, por ejemplo, la controversia sobre la relevancia teórica de la llamada investigación KOL («Knowledge and Opinion about Law»); cfr. Gerlinda Smaus, «Theorielosigkeit und politische Botmässigkeit der KOL-Untersuchungen», en Zeitschrift für Rechtssoziologie, 3 (1981), págs. 245-277; Erhard Blankenburg, «Die impliziten Theorien der KOL-Forschung», en Zeitschrift für Rechtssoziologie, 4 (1982), págs. 291-296; Gerlinda Smaus, «Eine Erwiderung aufBlankenhurg», loc. cit., págs. 297-304, 299 s.

${ }^{11}$ Una instructiva visión general ofrecen Konstanze Plett y Klaus A. Ziegert (comps.), Empirische Rechtsforschung zwischen Wissenschaft und Politik: Zur Problemlage rechtssoziologischer Auftragsforschung, Tubinga, 1984.

${ }^{12}$ Cfr. al respecto la visión general en Neil MacCormick/Ota Weinberger (comps.), An institutional Theory of Law. New Approaches to Legal Positivism, Dordrecht, 1986; Werner Krawietz, «Ansätze zu einem Neuen Institutionalismus in der modernen Rcchtstheorie der Gegenwart», en Juristen-Zeitung, 40 (1985), págs. 706-714.

${ }^{13}$ Klaus A. Ziegert, «Die Erfahrung rechtssoziologischer Forschung im internationalen Vergleich. Zugleich eine Zusammenfassung der Länderberichte», en Plett/Ziegert (comps.), loc. cit., págs. $159-173,172 \mathrm{~s}$.

${ }^{14}$ Cfr. al respecto, Heleen F. P. Iestwaart, «Some Notes of the Relations between Empirical Research and Theory», en Plett/Ziegert, op. cit., pág. 210-220, 211 ss., 216 ss. 
tratados de sociología jurídica, Raiser ${ }^{15}$ y Röhl ${ }^{16}$ ofrecen una visión panorámica de las diferentes teorías sobre las normas. Se trata aquí de enfoques y modelos de pensamiento que no son genuinamente sociológicos, sino que proceden de la teoría y la filosofía del Derecho ${ }^{17}$. En lo esencial, se trata de los siguientes enfoques que aquí tan sólo pueden ser brevemente esbozados:

a) El enfoque más importante es la teoría del mandato o teoría imperativa del Derecho (Hobbes, Austin, Kelsen, Olivecrona) que interpreta al Derecho como orden del legislador estatal dirigida a través de la norma jurídica 1) a los ciudadanos y 2) a la organización estatal o a partes de la misma.

b) La teoría imperativa se superpone, al menos parcialmente, con la teoría de la coacción y la sanción del Derecho (John Austin, Kelsen, Römer) que concibe a la amenaza o a la imposición de sanciones y a la coacción hasta la violencia física (medidas de ejecución de la pena) como elementos estructurales de la norma jurídica.

c) Ambos enfoques son complementados con la llamada teoría de la función o de los funcionarios jurídicos (Julius Stone, Roscoe Pound, Max Weber). Esta última parte de la concepción según la cual la función del Derecho consiste en 1) ejercer control social y 2) en llevar a cabo este control normalmente a través de un equipo de funcionarios judiciales especializados, especialmente a través de una burocracia de decisión altamente organizada, sobre todo a través del Estado.

d) Estas teorías son completadas y complementadas a través de la llamada teoría del reconocimiento (Habermas, Dreier, Alexy) según la cual el carácter jurídico de una norma depende, en última instancia, de la opinión de la comunidad, de partes de la misma o de un discurso racional ${ }^{18}$. Este último es entendido en el sentido de «un proceso de pensamiento y argumentación no institucionalizado». Por lo tanto, lo que esencialmente importa

${ }^{15}$ Thomas Raiser, Rechtssoziologie, Frankfurt del Meno, 1987, 199 ss.

${ }^{16}$ Werner Krawietz, Juristische Entscheidung und Wissenschaftliche Erkenntnis. Eine Untersuchung zum Verhältnis von dogmatischer Rechtswissenschaft und rechtswissenschaftlicher Grundlagenforschung, Viena/Nueva York, 1978, págs. 86 ss., 97 ss., 133 ss.

17

${ }^{18} \mathrm{Cfr}$. al respecto, sobre todo Ralf Dreier, Rechtsbegriff und Rechtsidee. Kants Rechtsbegriff und seine Bedeutung für die gegenewärtige Diskussion, Frankfurt del Meno, 1986, págs. 25 ss., 36 ss. Ver también Robert Alexy, «Rechtssystem und praktische Vernunft», en Rechtstheorie, 18 (1987), págs. 405-419, $418 \mathrm{~s}$. 
en el Derecho es su reconocimiento, su aceptación o, al menos, su aceptabilidad racional ${ }^{19}$.

6. Desgraciadamente, a partir de estas teorías no se puede inferir qué significación práctica y teórica tienen los distintos elementos estructurales del Derecho (orden, coacción, sanción, reconocimiento, aceptación, etc.) y ni siquiera se puede saber sí y por qué estos factores pertenecen a los elementos estructurales del Derecho.

a) La construcción de una teoría estructural del Derecho que procure satisfacer -desde el punto de vista teórico-jurídico, teórico social y también metateórico ${ }^{20}$ las condiciones histórico-sociales de los sistemas jurídicos actuales, sobre todo de los organizados estatalmente, está hasta el día de hoy afectada y oscurecida por el tratamiento altamente controvertido que se confiere a los elementos estructurales mencionados más arriba, sobre todo a los aspectos de la sanción y la coacción que, en algunos casos, están a cargo de un equipo de funcionarios judiciales.

b) Falta -y ésta es mi tesis central- un marco de referencia conceptualmente básico y coherente, es decir, una teoría marco del Derecho orientada hacia el permanente juego recíproco de normas, hechos y acción humana y que permita un tratamiento adecuado de estas cuestiones.

c) Algunos esbozos de una tal teoría marco, entendida como un Framework conceptual al servicio de la exposición e interpretación de los sistemas jurídicos, están contenidos en (i) la jurisprudencia sociológica alemana del siglo XIX, (ii) los clásicos enfoques de la sociología jurídica alemana, desde Ihering y Max Weber, (iii) los diversos nuevos enfoques con miras a un pensamiento

${ }^{19}$ Ralf Dreier, «Der Begriff des Rechts», en Neue Juristische Wochenschrift, 39 (1986), págs. 890-896, 890. Para una discusión crítica del concepto de Derecho de Dreier, cfr. Werner Krawietz, «Neues Naturrecht oder Rechtspositivismus?», Rechtstheorie», 18 (1987), págs. 209-254, 240 s. Cfr., además, la réplica de Ral Dreier, «Neues Naturrecht oder Rechtspositivismus?», en Rechtstheorie, 18 (1987), págs. 368-385.

${ }^{20}$ En la discusión, Herbert Simon ha advertido con razón contra una fundamentación del concepto del derecho desde el punto de vista de una teoría del poder. Los posibles puntos de partida y mi acceso a una teoría estructural institucionalista del poder y del Derecho son analizados en Werner Krawietz, «Verhältnis von Macht und Recht in staatlich organisierten Rechtssystemen», en Paul Hofmann y otros (comps.), Festschrift für Klemens Pleyer zum 65. Geburtstag, Colonia, 1986, págs. 217-235, 222 ss. 
jurídico institucionalista, especialmente la teoría de las instituciones y de los sistemas, de Schelsky y Luhmann.

Por ello, en lo que sigue, habré de proceder en tres pasos:

-Primeramente habré de ocuparme de la caracterización del concepto sociológico de la norma jurídica tal como es sostenida -siguiendo a Ihering, Max Weber y Theodor Geigerpor los representantes de una nueva teoría de las instituciones y los sistemas (Schelsky, Luhmann) y por la teoría de los sistemas de reglas del Derecho, que yo mismo he propuesto. Me concentraré aquí, sobre todo, en el examen de la cuestión de saber si los factores más arriba mencionados, por ejemplo, la sanción o la coacción por parte de los funcionarios judiciales, pertenecen a los elementos estructurales de la norma jurídica o del orden jurídico.

-En un segundo paso, consideraré la cuestión de si, con relación a los resultados obtenidos previamente, se puede hablar de un concepto monístico (estatista) del Derecho, según el cual el Derecho es sólo el Derecho estatal, o si, en cambio, hay que partir de un concepto pluralista (social) del Derecho, que acepta también la existencia de un Derecho no estatal.

-Por último, en un tercer paso, analizaré la cuestión de si, bajo las condiciones de una sociedad pluralista, el sistema jurídico estatalmente organizado puede seguir siendo caracterizado como un orden jerárquico o si no tiene más bien que ser entendido como una heterarquía antagónica de agrupaciones sociales y formaciones de sistemas.

II. Elementos estructurales del Derecho en la jurisprudencia sociológica y en la teoría del Derecho

En la literatura sociológica, Ihering, Max Weber y Theodor Geiger, que expusieran en sus obras teorías de las normas detalladamente elaboradas, suelen ser catalogados como partidarios de la teoría de la coacción y la sanción, es decir, de la teoría de los equipos judiciales. Esto sucede, por ejemplo, en Bechtler ${ }^{21}$, Raiser $^{22}$ y Röhl ${ }^{23}$. Algo similar sucede con los representantes de una teoría sociológica de las instituciones y sistemas del Derecho,

${ }^{21}$ Thomas W. Bechtler, Der soziologische Rechtsbegriff, Berlín, 1977, págs. 21 ss., 35 ss.

${ }^{22}$ Raiser, Rechtssoziologie, págs. 76 s., 99 ss., 231 s.

${ }^{23}$ Röhl, Rechtssoziologie, págs. 213 s., 216 s. 
como por ejemplo, Helmut Schelsky y Niklas Luhmann, quienes son presentados más bien como teóricos de las normas fieles al Estado, para quienes la coacción, es decir, la amenaza de la coacción y las sanciones formarían parte de los elementos estructurales del Derecho ${ }^{24}$. En lo que sigue, a través de una interpretación secundaria de estas teorías estructurales del Derecho, habré de demostrar que esta concepción es esencialmente incorrecta. Para ello examinaré 1) la teoría de las normas de Max Weber, 2) la de Theodor Geiger y 3) la de Niklas Luhmann.

\section{Max Weber}

Los actuales partidarios de la tesis de la coacción, la sanción y los equipos judiciales ${ }^{25}$ suelen invocar en su favor el $\S 6$ de la teoría sociológica de las categorías de Max Weber, expuesta en Economía y sociedad ${ }^{26}$. En este famoso pasaje se dice: «Un orden habrá de ser llamado Derecho cuando está garantizado externamente por la posibilidad de la coacción física y psíquica a través de la acción de un propio equipo especializado de personas, destinada a obligar su cumplimiento o a castigar su violación». Esto es considerado como una prueba de que Weber, per definitionem, habría apoyado la tesis del carácter coactivo del Derecho, es decir, su imposición por parte de un equipo judicial ${ }^{27}$.

1. Lo que aquí falsamente es citado como una supuesta definición de la norma, especialmente de la norma jurídica, no es ninguna definición del Derecho, sino simplemente un intento de Weber -quien aquí sigue a Ihering- de delimitar el Derecho frente a la «costumbre» y las «convenciones».

${ }^{24}$ Con respecto al primero, cfr. Hartmann Tyrell, «Gewalt, Zwang und die Institutionalisierung von Herrschaft: Versucht einer Neuinterpretation von Max Webers Herrsehaftsbegriff», en Rosemarie Pohlmann (comp.), Person und Institution -Helmut Schelsky gewidmet, Würzburz, 1980, págs. 59-92, $88 \mathrm{~s}$.

${ }^{25}$ Cfr. al respecto, Alan Hunt, The Sociological Movement in Law, Londres, 1978, págs. 103 ss.

${ }^{26} \mathrm{Cfr}$. al respecto y para lo que sigue, Max Weber, Wirtschaft und Gesellschaft. Grundriss der

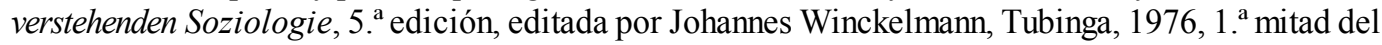
tomo I, §6b, pág. 17.

${ }^{27}$ Así, recientemente, Raiser, Rechtssoziologie, pág. 76, quien -en mi opinión incorrectamentecalifica a Max Weber como «el padre de la llamada teoría coactiva del derecho... hoy dominante en la sociología jurídica». 
a) Weber mismo manifiesta expresamente que lo que le interesa aquí no es una definición del concepto de Derecho, es decir, una definición del concepto jurídico de norma en tanto tal, sino establecer una distinción entre el Derecho y otras normas sociales. Por ello señala que el concepto «derecho» podría «ser delimitado para otros fines de manera totalmente distinta» ${ }^{28}$.

b) En este contexto, Weber tampoco analiza la estructura de la norma jurídica o del orden jurídico, sino que la presupone como ya dada.

2. Tampoco le interesa aquí a Weber la definición del Derecho, sino una cuestión totalmente distinta, es decir, la cuestión de saber cómo puede «garantizarse» la «legitimidad de un orden», justamente el del Derecho ${ }^{29}$. Weber considera que una garantía de este tipo -entendida en el sentido de garantía de posibilidades específicas de eficacia- puede muy bien ser obtenida en la medida en que se logre apoyar, confirmar y reforzar permanentemente, es decir, garantizar de esta manera, las «expectativas» específicas que habitualmente están vinculadas con el Derecho.

a) Por tanto, la hasta ahora dominante concepción que aquí he criticado no toma en cuenta el hecho de que para Weber entre los elementos estructurales esenciales del Derecho se cuentan sobre todo «expectativas» normativas bien específicas y socialmente establecidas.

b) Estas «expectativas», articuladas con los medios del lenguaje jurídico, normativamente establecidas con carácter de permanencia, pueden, a su vez, ser «garantizadas» «a través de expectativas de un tipo especial»» ${ }^{30}$ en el sentido de que con el cumplimiento del Derecho se espera también la satisfacción de determinadas expectativas especiales.

c) Esta forma de garantía del Derecho se lleva a cabo sobre todo «a través de expectativas de consecuencias externas específicas $\rangle^{31}$, tales como, por ejemplo, sanciones, coacción y violencia por parte de la autoridad estatal.

3. Además, la tesis del carácter coactivo del Derecho, falsamente atribuida a Weber, no toma en cuenta el estado de la

\footnotetext{
${ }^{28}$ Weber, Wirtschaft und Gesellschaft, loc. cit., pág. 18,

${ }^{29}$ Ibid., pág. 17.

${ }^{30}$ Ibid., pág. 17.

${ }^{31}$ Ibid., pág. 17.
} 
investigación actual sobre Max Weber. Esta es mi objeción crítica básica. En efecto, los «fundamentos» de la teoría y la sociología del Derecho de Weber no se encuentran en Economía y sociedad y por tanto tampoco en su «Sociología del Derecho» ${ }^{32}$ que es una parte de esta obra ${ }^{33}$, sino en su famosa crítica a la teoría stammleriana del Derecho y la filosofía del Derecho del año 1907 que ya contiene el germen de la fundamentación de su teoría sociológica de las normas ${ }^{34}$.

a) En esta investigación, Weber concibe -desde el punto de vista del lenguaje del Derecho- a la «norma» y a la «regla jurídica» vivida, es decir, traducida en comportamiento humano, como elementos estructurales de una convivencia social regulada institucionalmente. Esto lo muestra en una comparación de las reglas jurídicas con las reglas de un juego tomando como ejemplo el «Skat» (especie de tresillo, N. del T.), tal como lo he expuesto en otro trabajo ${ }^{35}$.

b) Tal como lo demuestra Weber a través de su comparación entre las reglas del juego y las reglas jurídicas tomando el «paradigma del Skat», las reglas del juego -al igual que las del Derecho- constituyen un sistema de puntos de vista de orientación establecido institucionalmente con carácter de permanencia, que estructura el campo de acción de los jugadores. Esto permite considerar el cumplimiento y la aplicación de las reglas del juego como «presupuestos»» ${ }^{36}$ de un juego concreto, sin que con ello se diga nada acerca de su desarrollo y resultado reales.

c) Efectivamente, todas las reglas del juego social (incluyendo las del Derecho) permiten formular suposiciones acerca de la forma de jugar de los jugadores con mayor seguridad que en el

${ }^{32}$ Max Weber, Wirtschaf und Gesellschaft, segundo medio tomo, cap. VII, §§ 1-8, págs. 387 ss.

${ }^{33}$ Por consiguiente, la teoría de las normas (incluyendo las del Derecho) de la que se hablará en lo que sigue, no está contenida o no lo está íntegramente en la «sociología del Derecho», de Max Weber.

${ }^{34}$ Max Weber, «R. Stammler 'Überwindung' der materialischen Geschichtsauffassung», en, del

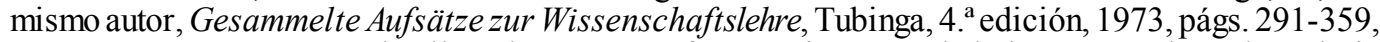
322 s., 343 ss. Para más detalles al respecto, cfr. Krawietz, «Verhältnis von Macht und Recht in staatlich organisierten Rechtssystemen», pág. 227 s.

${ }^{35}$ Werner Krawietz, «Zur Korrelation von Rachtsfrage und Tatfrage», en Norbert Achterberg (comp.), Rechtsprechungslehre. Internationales Symposium Münster 1984, Colonia, 1986, págs. 517-550, 529 ss., 547 ss. $339 \mathrm{~s}$.

${ }^{36}$ Weber, «R. Stammlers ‘Überwindung’ der materalistischen Geschichtsauffassung», pág. 337 s., 
caso en que no existieran estas reglas, ya que también las actividades de los jugadores están sometidas a estas premisas normativas («expectativas») ${ }^{37}$. Por lo tanto, al igual que en el caso de las reglas del juego, puede considerarse que la función decisiva de todas las reglas jurídicas socialmente establecidas e institucionalizadas consiste en que cada cual «puede orientar su propio comportamiento a través de las expectativas inequívocas creadas por ellas» ${ }^{38}$. Así pues, tampoco aquí el elemento estructural decisivo de la regla jurídica es la amenaza de la sanción o la coacción, sino la «expectativa» normativa directamente expresada en la prescripción jurídica y con respecto a la cual se puede suponer que para el jugador, es decir, para el destinatario de la norma jurídica, es obligatoria, o sea, que debe cumplirla.

\section{Theodor Geiger}

En contra de una opinión muy difundida, compartida también por Raiser ${ }^{39}$, y Röhl ${ }^{40}$, tampoco Theodor Geiger puede ser entendido como representante de la teoría de la coacción y la sanción, a pesar de que recientemente Dreier $^{41}$ quiere ver en él hasta un representante del concepto estatista del Derecho.

1. En su definición normativo-realista del concepto del Derecho, Geiger parte de la distinción -dominante en el pensamiento jurídico-sociológico alemán desde Ihering y Max Weber- entre las «proposiciones normativas» (normas escritas, normas orales) y la «norma subsistente» ${ }^{42}$ que subyace al comportamiento humano y está por así decirlo «ínsita» en él. Esta es, según él, la «norma en sentido propiamente dicho».

a) En todos los casos, la proposición normativa contiene una «expectativa exigente», determinada situacionalmente, que -sostenida y apoyada por el respectivo «grupo portador del orden»- se dirige a la «conducta» de los respectivos destinatarios de la

${ }^{37}$ Max Weber, «Über einige Kategorien der verstehenden Soziologie» (1913), en, del mismo autor, Gesammelte Ausütze zur Wissenschaftslehre, editados por Johannes Winckelmann, Tubinga, 4. ${ }^{\mathrm{a}}$ edición, 1973, págs. 427-474, 439 ss., 442 ss.

${ }^{38}$ Ibid., págs. 440, 473 s. Subrayado de la cita de W. K.

${ }^{39}$ Raiser, Rechtssoziologie, págs. 99 ss., 231.

${ }^{40}$ Röhl, Rechtssoziologie, pág. 99 ss., 231.

${ }^{41}$ Dreier, NJW, 1986, pág. 890.

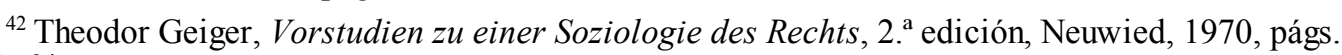
$58,64 \mathrm{~s}$. 
norma. Por tanto, a todo «orden» social (incluyendo el del derecho como una «coordinación de conductas de tipo especial») ${ }^{43}$ subyacen determinadas expectativas de comportamiento tipificantes ${ }^{44}$.

b) Así pues, para la comprensión de la teoría de las normas de Geiger lo primordialmente relevante no es la disposición a la reacción colectiva (organizada) (sanción, coacción), sino el concepto de expectativa normativa («expectativa exigente», «expectativa de conducta») $)^{45}$ que en su teoría de las normas, especialmente las jurídicas, tiene una importancia central.

c) Esto se expresa también en la distinción de Geiger entre «norma de acción»y «norma de reacción» (o: norma «primaria» y «secundaria») que pueden pero no tienen por qué ser «conectadas» recíprocamente ${ }^{46}$. Como comparación, puede aquí recordarse a Kant para quien «derecho y competencia para coaccionar... (significan) lo mismo» ${ }^{47}$, mientras que Geiger, correctamente, supone la conexión entre dos normas jurídicas.

2. Pero, con esta fundamentación teórico-normativa desaparecen también los presupuestos para el supuesto estatismo de Geiger. Ciertamente, según él, el «control del orden» es un elemento esencial de todo el «mecanismo del orden». Sin embargo, en primera línea no se trata aquí del apoyo por parte del Estado al orden socialmente establecido sino de una forma de autocontrol social de la vida social del grupo a través del propio "grupo portador del orden», es decir, a través del respectivo «integrado» o, como diríamos hoy, del respectivo sistema social ${ }^{48}$. Geiger reconoce, por cierto, también una "vinculación con el "Estado" $\gg "$, pero en este caso se trata de un apoyo y garantía adicionales al orden jurídico de la vida ya establecido.

3. En contra de lo sostenido por una concepción actualmente muy difundida pero incorrecta, cabe afirmar que en la teoría y en la sociología del Derecho alemanas, a más tardar desde Ihering ${ }^{50}$ y Max Weber hasta Theodor Geiger y Schelsky ${ }^{51}$, ni la

${ }^{43}$ Geiger, op. cit., págs. 48 s., 94 ss., 125 s.

${ }^{44}$ Ibid., págs. $49 \mathrm{~s}$.

${ }^{45}$ Ibid., págs. 49, 65.

${ }^{46}$ Ibid., pág. 145.

${ }^{47}$ Kant $W W$, IV, págs. $339 \mathrm{~s}$.

${ }^{48}$ Geiger, Vorstudien, págs. 58, $64 \mathrm{~s}$.

${ }^{49}$ Ibid., págs. $127 \mathrm{~s}$.

${ }^{50}$ Con razón críticamente frente a la concepción que trataba de reducir el concepto de Derecho a la «posibilidad de la coacción garantizada por la ley», ya Rudolph von Ihering, Geist des römischen Rechts auf den verschiedenen Stufen 
coacción ni la sanción son consideradas como elementos estructurales del Derecho. Se trata aquí más bien de meros fenómenos secundarios de la obediencia, mejor dicho, desobediencia del Derecho.

\section{Niklas Luhmann}

En su teoría del sistema jurídico, Luhmann rechaza expresamente -y sobre este punto no necesito extenderme- todo intento de considerar a la coacción o a la «característica de coaccionabilidad» como criterio del concepto del Derecho. Se niega, sobre todo, a definir al Derecho «a través del medio de la violencia física» o, más exactamente, «a través de la aplicabilidad legítima (reconocida socialmente) de la violencia física en caso de violaciones de la norma $»^{52}$. Consecuentemente se niega también a «definir el concepto de norma a través de la disposición a imponer sanciones en casos de desilusión $»^{53}$.

1. Por tanto, para Luhmann, al igual que para Weber, Geiger y Schelsky, el derecho «no es en modo alguno primariamente un orden coactivo, sino un medio para facilitar expectativas» que, con la ayuda de las reglas del Derecho («selección de expectativas de comportamiento») es establecido institucionalmente con carácter de permanencia y funciona como una «estructura de los sistemas sociales» más o menos generalizada ${ }^{54}$.

2. Sobre el trasfondo de esta interpretación secundaria de Weber y Geiger se ve claramente por qué en la conocida definición

seiner Entwicklung, parte III, 1 (1865), citado de acuerdo con la 9. a edición, reimpresión Aalen 1968, págs. $327 \mathrm{~s}$. La lanza dirigida en contra de «Kant y su escuela» en el sentido de que no habrían ido «más allá de la forma externa de presentación del Derecho, la coacción», ibíd., págs. 328 s., parece estar justificada ya que con razón Ihering considera que la esencia de la norma jurídica no consiste «en su mera formulación sino en su cumplimiento». Según Ihering, las meras «ideas del Derecho» se convierten en «Derecho» como un «poder que conforma y domina la vida», sólo «a través de la realización constante e ininterrumpida». Igualmente: August Thon, Rechtsnorm und subjektives Recht, Weimar, 1878, págs. 1 s.: «La coacción no es un elemento esencial del concepto del Derecho.»

${ }^{51}$ Invocando a Ihering y a Max Weber, esto lo subraya Helmut Sehelsky, «Systemfunktionaler, anthropologischer und personfunktionaler Ansatz der Rechtssoziologie», en Jahrbuch für Rechtssoziologie und Rechtstheorie, 1 (1970), págs. 37-89, 51 ss., 66 ss., 75 s.

${ }^{52}$ Niklas Luhmann, Rechtssoziologie, Reinbek, 1972, págs, 107 s., 219 ss.

${ }^{53}$ Ibíd., págs. $60 \mathrm{~s}$.

${ }^{54}$ Ibid., págs. 99 s. Subrayado de W. K. 
del Derecho de Luhmann no aparecen la coacción ni la sanción como así tampoco la coaccionabilidad a través del equipo judicial estatal. En cambio, otorga importancia central al concepto de expectativa normativa cuando dice: «Podemos ahora definir al Derecho como estructura de un sistema social basado en una congruente generalización de las expectativas normativas de comportamiento.» ${ }^{55} \mathrm{Su}$ definición muestra en cuán gran medida la teoría de las normas de Luhmann responde a la tradición de pensamiento de la teoría y la sociología del Derecho alemanas.

Llegamos con esto al resultado provisional de que por lo que respecta al concepto sociológico del Derecho -al menos en la teoría y en la sociología del Derecho alemanasdesde Thering, Max Weber y Geiger hasta Scheisky y Luhmann, se considera que el aporte principal de todas las instituciones jurídicas reside en la creación normativa de expectativas. Así pues, ni el reconocimiento, ni la coacción ni la sanción ni la existencia de un equipo judicial constituyen el elemento estructural decisivo de la norma jurídica, sino una expectativa expresiva (prescriptiva) seleccionada por la norma jurídica, establecida con carácter de permanencia y eficacia. Si no me equivoco, esta concepción coincide en sus resultados con el prescriptivismo de la concepción de las normas de Georg Henrik von Wright ${ }^{56}$ y con el expresivismo de la teoría de las normas de Alchourrón-Bulygin ${ }^{57}$.

El concepto de la expectativa normativa formulada en el lenguaje jurídico se convierte así en una categoría central de la teoría y la sociología del Derecho. Sin embargo, de acuerdo con la concepción del Derecho aquí sostenida ${ }^{58}-y$ justamente aquí reside la diferencia con la teoría de las normas de Alchourrón-Bulygin y Von Wright, que colocan en primer plano el carácter

${ }^{55}$ Ibid., pág. 105.

${ }^{56}$ Cfr. al respecto, sobre todo Georg Henrik von Wright, Norm und Handlung, Königstein, 1979, págs. 18 ss., 23 ss., con una visión general de los significados principales, especies y tipos de normas.

${ }^{57}$ Para mayor detalle, cfr. Carlos E. Alchourrón/Eugenio Bulygin, «Expressive versus hyletische Konzeption der Normen?», en Werner Krawietz/-Walter Ott (comps.), Formalismus und Phänomenologie im Rechtsdenken der Gegenwart, Berlín, 1987, págs. 143-172, 145.

${ }^{58}$ Werner Krawietz, «Die Normentheorie Helmut Schelsky als Form eines Neuen Institutionalismus im Rechtsdenken der Gegenwart», en Horst Baier (comp.), Helmut Scheisky -ein Soziologie in der Bundesrepublik, Stuttgart, 1986, págs. 114-148; del mismo autor, «Rechtssystem als Institution? über die Grundlagen von Helmut Schelskys sinnkritischer Institutionentheorie», en Rechtstheorie Beihelft, 6 (1984), págs. 209-243. 
lingüístico de la norma jurídica y del orden jurídico- todas las expectativas normativas expresadas en el lenguaje jurídico resultan estar decididamente determinadas socio-estructuralmente y acuñadas por las instituciones, las organizaciones y los sistemas sociales. Desde el punto de vista del nuevo institucionalismo de la teoría de los sistemas del Derecho que yo sostengo, sólo es posible un adecuado acceso a la estructura de expectativa normativa del Derecho si se concibe al Derecho como incluido en las diversas formas de la vida social. La regularidad del comportamiento humano, especialmente de los actos jurídicos, no se pone de manifiesto si -de acuerdo con un positivismo jurídico que desgraciadamente hasta el día de hoy ha seguido signando y determinando el positivismo jurídico institucionalista- se intenta limitar y reducir el conocimiento del Derecho a las proposiciones independizadas (proposiciones normativas) y su significado. Ello es sólo posible si se concibe la regulación jurídica como resultado de actividades normativas continuadas, con cuya ayuda el orden jurídico se autoproduce y reproduce.

\section{III. ¿Monismo o pluralismo del sistema de reglas sociales del Derecho?}

1. Hasta ahora ha quedado pendiente la cuestión de saber en qué consiste el aporte de la teoría y la sociología del Derecho alemanas que -desde Ihering, Max Weber y Theodor Geiger-se ha desarrollado tan rápidamente en nuestro siglo, sobre todo en los decenios después de la segunda guerra mundial. Pienso aquí especialmente en las teorías del Derecho dese comienzos de los años 60, en la teoría de las instituciones y de los sistemas de Schelsky y Luhmann, que se ha desarrollado de una manera extraordinariamente rápida y que hasta el día de hoy ejerce una influencia considerable en el contexto internacional ${ }^{59}$.

a) Los aportes de la teoría de las instituciones y de los sistemas residen, por una parte, en su potencial crítico ${ }^{60}$, que beneficia,

${ }^{59}$ Para mayor detalle, cfr. Werner Krawietz, «Paradigms, positions and prospects of rationality The changing foundation of law in institutional and systems theory», en Anders Bratholm y otros (comps.), Samfunn-Rett-Rettferdighet. Festskrift til Torstein Eckhoffs 70 -Arsdag, Oslo, 1986, págs. $452-465,456$ ss., $460 \mathrm{~s}$.

${ }^{60}$ Cfr. Werner Krawietz, «Begründung des Rechts -anthropologisch betrachtet: zur Institutionentheorie von Weinberger und Schelsky», en Theorie der Normen. Festgabe für Ota Weinberger zum 65. Geburstag, Berlín, 1984, 
sobre todo, la crítica a las tradicionales teorías de las normas, desde la teoría del mandato y la teoría imperativa hasta las diversas teorías del reconocimiento.

b) La teoría de las instituciones y los sistemas ${ }^{61}$ al partir de la suposición de que el Derecho -desde el punto de vista de su génesis- surge en las instituciones sociales y en las otras organizaciones sociales, por ejemplo, en la propiedad, la familia y otros sistemas de acciones más o menos burocratizados, como los sindicatos, iglesias, etc., logra demostrar que la concepción tradicional de un monopolio estatal -o también de sólo una prerrogativa estatal para la producción del Derecho- necesita ser corregida.

c) Sobre este trasfondo, tiene que parecer totalmente equivocado un concepto del Derecho puramente estatal, según el cual todo Derecho es Derecho estatal. La teoría de las instituciones y los sistemas, al sustituir las concepciones difusas de «sociedad» por una red de relaciones sociales, tendida entre todos los individuos, las instituciones, grupos y organizaciones sociales hasta las burocracias de decisión estatales, inter y supraestatales, puede concebir las normas jurídicas, es decir, el orden jurídico en su totalidad, como elementos y partes constitutivas de las respectivas estructuras sociales de expectativas que, a través de los medios del Derecho, son establecidas en la convivencia humana ${ }^{62}$.

2. Sólo porque la teoría de las instituciones y los sistemas concibe a los aportes de orden del respectivo Derecho vigente

págs. 541-556, 551 ss. Cfr. además, Recht und Institution. Helmut Schelsky-Gedächtnissymposion 1985, editado por la Rechtswis-senschaftliche Fakultät der Universität Münster, Berlín, 1985; Krawietz, «Recht und moderne Systemtheorie», en Rechtstheorie Beiheft, 10 (1986), págs. 281-309, 305 ss.

${ }^{61}$ Frente al aquí propuesto enfoque conceptual de integración de las teorías de las instituciones y los sistemas, Jürgen Habermas -en el fondo con razón- ha objetado verbalmente que quizás de esta manera la teoría de los sistemas sociales de Luhmann es colocada en una relación demasiado estrecha y por lo tanto objetivamente no adecuada con la teoría de las instituciones. Pienso que esta objeción debe ser tomada en cuenta pero no es decisiva, ya que la teoría sociológica del derecho de Luhmann, especialmente su "teoría del sistema jurídico», se basa fundamentalmente en una teoría de la institucionalización. Cfr. al respecto, Niklas Luhmann, Rechtssoziologie, 2. ${ }^{a}$ edición, Opladen, 1980, págs. 64 ss., 73 ss., 94 ss. Además, de esta manera, se posibilita, al mismo tiempo, una consideración crítica del positivismo jurídico institucionalista.

${ }^{62}$ Para mayor detalle, cfr. Werner Krawietz, «Identität oder Einheit des Rechtssystems?», en Mitsukuni Yasaki y otros (comps.), Japanisches und europäisches Rechtsdenken -Versuch einer Synthese philosophischer Grundlagen, Berlín, 1985, págs. 233-277, 257 s., 259 ss. 
como distribuidos en determinadas instituciones, sistemas y organizaciones sociales que actúan respectivamente como sistemas sociales y concretos de acción -por ejemplo, como una empresa tal como Mercedes Benz, como un centro universitario (con su organización interna) o como una administración municipal con su burocracia para la toma de decisionespuede explicar cómo en la sociedad moderna, es posible el orden del Derecho ${ }^{63}$.

a) Las dimensiones de esta problemática jurídica del orden se ponen de manifiesto si uno toma en cuenta que en la actualidad, tan sólo en Europa, viven 492 millones de personas, de los cuales unos 60 millones en la República Federal de Alemania y otros 321 millones en los doce países miembros de la CE, cuyas relaciones sociales son estructuradas y guiadas dentro del marco de los sistemas jurídicos estatalmente organizados y competentes en cada caso, a través de los medios del Derecho respectivamente vigente.

b) Prescindo aquí del hecho de que con respecto a los sistemas jurídicos -en lo esencial estatales- que aquí están implicados, existen también actividades que superan sus límites y que están sometidas a una regulación a través de los medios del Derecho comunitario o del Derecho internacional. La tarea de regular a través del Derecho una cantidad tan inmensa de interacciones reales-posibles constituye una pesada sobrecarga para todo sistema jurídico,

3. Bajo estos presupuestos -aquí tan sólo esbozados- me parece que, para una concepción de la teoría de las normas de una teoría de las instituciones y los sistemas, es casi inevitable renunciar a una concepción puramente monista (estatista) del Derecho.

a) Habitualmente, en la teoría y la sociología del Derecho, se entiende por monismo, es decir, por un concepto monista del Derecho, la concepción según la cual el Derecho, per definitionem, tiene que ser entendido sólo como Derecho estatal y por consiguiente, sólo el Derecho impuesto por el Estado, o de alguna manera derivable de él, merece este nombre.

b) De acuerdo con ello, algunos sociólogos del Derecho, por ejemplo Röhl, sostiene la concepción de que «no puede hablarse de conocimiento ya que sólo (se trataría, W. K.) de una cuestión de definición» ${ }^{64}$. Ciertamente esto no es correcto.

${ }^{63}$ Krawietz, «Recht und moderne Systemtheorie», págs, 283 ss., 291 ss., 284 y siguientes.

${ }^{64}$ Röhl, Rechtssoziologie, pág. 218. 
c) Un análisis de la realidad social de sistemas de reglas jurídicas concretamente existentes, que pueden ser identificadas como tales porque a través de la formación social de sistemas con medios del Derecho, las actividades interhumanas son efectivamente esperables y por tanto calculables $^{65}$, puede mostrar muy rápidamente que existe una pluralidad de formaciones sociales de sistemas que -en el mejor de los casos- puede ser regulada y conducida sólo parcialmente a través del Derecho estatal. En esta medida, puede demostrarse que existe (1) no sólo un Derecho estatal, sino (2) un Derecho social, cuya existencia, cualquiera que pueda ser la forma como sea interpretada comprensiva o empíricamente, sólo puede ser tomada en cuenta a través de un concepto pluralista ${ }^{66}$, del Derecho.

IV. ¿Jerarquía o heterarquía de los sistemas sociales de reglas del Derecho?

1. Un concepto sociológico del Derecho no puede concentrarse exclusivamente en el Estado y su Derecho como el médium del comportamiento político ${ }^{67}$. En la teoría y en la sociología del Derecho hay que trabajar siempre simultáneamente con diversas referencias sistémicas sociales.

a) También en los sistemas jurídicos estatalmente organizados de la sociedad moderna hay que tener en cuenta la posibilidad de que, junto con el Derecho estatal, exista también un Derecho no estatal, es decir, un Derecho genuinamente social. Esto significa también que la teoría y la sociología del Derecho -prescindiendo de los sistemas jurídicos estatalmente organizados y de sus mecanismos político-jurídicos de decisión- tendrán que dedicar en el futuro más atención que hasta ahora a las fuerzas sociales que constituyen la comunidad y actúan autorreguladoramente.

b) Existen también sociedades que no conocen en absoluto un Estado burocratizado en sentido moderno ${ }^{68}$, pero que, sin embargo, poseen un orden jurídico.

${ }^{65}$ Krawietz, «Normentheorie Helmut Schelskys», págs. $138 \mathrm{~s}$.

${ }^{66}$ Cfr. al respecto, Peter Sack/Elizabeth Minchin (comps.). Legal Pluralism, Camberra, 1986.

${ }^{67}$ Cfr. una opinión diferente en Röhl, Rechtssoziologie, págs. $220 \mathrm{~s}$.

${ }^{68} \mathrm{Al}$ respecto, Peter Sack, «Legal Pluralism»,en, del mismo autor/Minchin (comps.), Legal Pluralism, Camberra, 1986, págs. 1-16, 5 ss. 
c) De lo que se trata -al menos en el campo de la teoría del Derecho y la sociedades nada más y nada menos que del abandono de un concepto positivistamente reducido del Derecho. Un concepto sociológico del Derecho requiere su ampliación a través de la concepción de que todo Derecho no es primordialmente un producto de la decisión del equipo judicial, sino, sobre todo, un orden vivido, es decir, realmente vigente, normativamente eficaz, de la experiencia vital y del comportamiento de las personas, cuyas estructuras de expectativas institucionalmente establecidas con carácter de permanencia y su distribución de derechos y deberes dependen y seguirán dependiendo de la formación social de sistemas.

2. En el sistema jurídico estatalmente (e interestatalmente) organizado de la sociedad moderna no existe -tal como lo puede demostrar la interpretación de la teoría de los sistemas- ni una cúspide ni un centro desde el cual pudiera llevarse a cabo una conducción central intrasistémica ${ }^{69}$.

a) Una conducción central tal como en estructuras de dominación anteriores -por ejemplo, por el monarca en la cúspide de una comunidad: un zar, un emperador, un déspota, etc.- quizá pudo ser practicada -a pesar de que también esta posibilidad tiene que ser considerada con escepticismo debido a sus presupuestos y limitaciones inmanentes-, está prácticamente excluida en el sistema jurídico moderno, organizado de acuerdo con el principio de la división del trabajo, con sus órganos de decisión funcionalmente diferenciados (legislación, gobierno, administración, poder judicial). Está ya excluida por el hecho de que las diferentes partes y subsistemas son aprehensibles y controlables sólo limitadamente, es decir, son hasta cierto punto «black boxes».

b) Ciertamente es posible, a través de la organización intrasistémica, establecer una jerarquía de diversos niveles de decisión (constitucional, legislativo, ordenanzas jurídicas, etc.) y de portadores de decisión (poder legislativo, ejecutivo, judicial, federación, Estados federados, municipios), pero estas autojerarquizaciones del sistema jurídico no logran impedir que en todos los niveles de decisión influyan en las decisiones también fuerzas de la autoconducción a través de los diferentes sistemas parciales y los subsistemas ${ }^{70}$.

\footnotetext{
${ }^{69}$ Werner Krawietz, Recht als Regelsystem, Wiesbaden, 1984, págs. 136 ss., 140 s.

${ }^{70}$ Krawietz, op. cit., págs. 117 s., 131 s., 150 ss.
} 
c) Por ello, la conducción y el control de toda la sociedad con los medios del Derecho no pueden ser ya considerados como un sistema monocentrista, jerárquicamente organizado, de varios niveles, de organismos de decisión recíprocamente independientes. La vida social, en todas sus formas de vida, tiene, por lo menos, que ser evaluada también bajo el aspecto de una real-posible heterarquía de decisores y organismos de decisión autónomos.

3. Por último, desde el punto de vista del Derecho social y de un concepto sociológico del Derecho, tal como el sugerido por las investigaciones de la teoría de las instituciones y los sistemas, hay que señalar que los sistemas sociales -entendidos aquí en el sentido de sociedades regionales (por ejemplo, la sociedad germano occidental) que son respectivamente conducidas por sistemas jurídicos estatalmente organizados- en lo esencial no están construidos jerárquica sino heterárquicamente.

a) Por lo que respecta a la coordinación de estos desarrollos divergentes, hay que abandonar la idea de pretender ordenarlos jerárquicamente a todos, por ejemplo, dentro de una nueva organización intra-sistema que habría que crear.

b) Tales contextos sistémicos amplios no pueden -si es que han de seguir siendo susceptibles de aplicación y desarrollo- ser ordenados jerárquicamente, sino que deben ser confiados a la heterarquía de las fluctuantes relaciones inter-sistema, que prácticamente excluyen una conducción y control plenos realizados, por así decirlo, desde arriba hacia abajo.

\section{Resultado y conclusiones}

De las aquí realizadas reinterpretación y reformulación del concepto del Derecho sostenido en la teoría y la sociología del Derecho desde Ihering, resulta una serie de consecuencias que en este trabajo pueden tan sólo ser esbozadas:

1) En la jurisprudencia no puede continuarse con la apología de una comprensión positivista del Derecho, tal como la expresada por los actuales partidarios de la teoría de la coacción y la sanción o de la teoría del reconocimiento del Derecho. A más tardar desde Ihering, la jurisprudencia dispone de un concepto del Derecho, fundamentado sociológica y filosóficamente y ya 
no positivista ${ }^{71}$. Posee, pues, una perspectiva del problema que ya no trata de separar al Derecho, con todos sus condicionamientos histórico-sociales, de los contextos institucionales, organizativos y sistémicos. Por el contrario, lo considera normativa-realistamente, en su estructura y sus funciones.

2. A diferencia de lo que sostiene una opinión muy difundida, puede afirmarse que desde Thering y Max Weber los enfoques clásicos de la teoría y la sociología del Derecho alemanas no están totalmente determinados y acunados por el llamado carácter imperativo $y$ coactivo del Derecho, según el cual todo Derecho está esencialmente caracterizado por la sanción o la coacción con las que en caso necesario, pueden ser impuestas sus prescripciones. La decisión de conflictos y la aplicación del poder coactivo tienen que ser fáctica y conceptualmente separados.

3. Por tanto, de la aquí presentada crítica a la teoría de la coacción o sanción y a la teoría del reconocimiento ${ }^{72}$ del Derecho no se sigue que los aspectos de la sanción y del reconocimiento (aceptación) carezcan de relevancia práctica en la realidad social del Derecho. Justamente lo contrario es el caso. Lo que me importa en el presente contexto es poner claramente de manifiesto -desde el punto de vista de una consideración realista-normativa, sobre todo desde la perspectiva de la teoría de las instituciones y los sistemas- que el aspecto de la coacción, de la sanción y del reconocimiento o aceptación del Derecho, no pertenecen a los elementos estructurales del Derecho, es decir, del orden jurídico.

4. Tampoco basta referir el concepto de Derecho exclusivamente al Estado, ya que el Derecho estatal -desde el punto de

${ }^{71}$ La concepción opuesta sostenida por Karl Olivecrona, «Iherings Rechtspositivismus im Lichte der heutige Wissenschaft», Frans Wieacker/Christian Wollschläger (comps.), Iherings Erbe, Gotinga, 1970, págs. 165-176, no responde al estado actual de la investigación. Cfr. al respecto, Jan Schröder, «Rudolph von Ihering», en Gerd Kleinheyer/Jan Schröder (comps.), Deutsche Juristen aus fünf Jahrhunderten, 2. ${ }^{\mathrm{a}}$ edición, Heidelberg, 1983, págs. 132-137, 135, quien con respecto a la «importancia» de Thering para la teoría jurídica del siglo XIX observa con toda razón: «Al intentar explicar el Derecho a partir de sus fundamentos sociales, rechaza tanto el positivismo jurídico (como limitación a las proposiciones independizadas del Derecho positivo) como todo tipo de iusnaturalismo.»

${ }^{72}$ Tal como lo señalara en su observación verbal Jürgen Habermas, esto es quizás demasiado poco. En mi descargo, deseo hacer referencia a una publicación mía anterior: «Sind Zwang und Anerkennung Strukturelemente der Rechtsnorm?», enOta Weinberger/Werner Krawietz (comps.), Reine Rechtslehre im Spiegel ihrer Fortsetzer und Kritiker, Viena/Nueva York, 1988, págs. 315-369, 327 ss., 339 ss. 
vista teórico jurídico y jurídico-sociológico- no es la única forma posible del Derecho. Naturalmente, la más arriba propuesta orientación complementaria de la consideración del Derecho hacia las fuentes sociales del Derecho no excluye sino que incluye la siempre insoslayable y necesaria orientación hacia las fuentes estatales (formales) del Derecho.

5. Pero, de acuerdo con todo esto -también teniendo en cuenta siempre las diversas referencias sistémicas- los elementos estructurales decisivos de la norma jurídica no son ni el reconocimiento ni la coacción ni la sanción sino las expectativas jurídicas desarrolladas a través de las normas del Derecho respectivamente vigente, con sus efectos constitutivos, expresivos (prescriptivos). Consecuentemente, pasan al centro de la investigación teórico-jurídica y sociológico-jurídica las expectativas normativas de comportamiento que subyacen a todas las formas vitales jurídicas de la formación de la comunidad humana.

6. Por tanto, la función decisiva de todas las reglas jurídicas establecidas e institucionalizadas socialmente de esta manera, en tanto «artefactos» humanos, puede consistir en que cada cual pueda «orientar su propia acción por expectativas unívocas y creadas por ellas» ${ }^{73}$. El aporte central de todas las instituciones jurídicas, organizaciones y sistemas sociales reside, pues, en el nivel de la formación normativa de expectativas.

7. Por consiguiente, las concepciones mencionadas al comienzo, desde la teoría de la coacción hasta la teoría del reconocimiento -tanto tomadas individualmente como en su conjunto-, son poco adecuadas para proporcionar un Framework teórico-jurídico conceptualmente básico que no sólo ofrezca 1) un marco de significado para el actuar normativamente conducido, sino 2) que pueda servir, al mismo tiempo, como marco de referencia para interpretaciones y explicaciones científicas. Esto podría lograrlo según mi concepción -que aquí no puedo exponer con mayor detalle- una teoría de las instituciones $\mathrm{y}$ de los sistemas que conciba a los principios jurídicos y a las reglas jurídicas como elementos normativos de las instituciones y de los sistemas sociales que orientan el actuar humano a través de las expectativas que ellos establecen.

(Trad. de Ernesto Garzón Valdés)

\footnotetext{
${ }^{73}$ Weber, «Über einige Kategorien der verstehenden Soziologie», págs. 473 y s. Subrayado de W. K.
}

DOXA 5 (1988) 